\title{
Clinical Features of Congenital Pseudarthrosis of the Tibia in Childrenखa Study Focusing on 514 Cases in China
}

\section{Yijun Zhou}

Jinan University

\section{Qian Tan}

Hunan Children's Hospital

Kun Liu

Hunan Children's Hospital

Yaoxi Liu

Hunan Children's Hospital

\section{Guanghui Zhu}

Hunan Children's Hospital

Haibo Mei ( $\nabla$ meihaibo@sohu.com )

Hunan children's hospital https://orcid.org/0000-0002-9434-1716

\section{Ge Yang}

Hunan children's hospital

\section{Research}

Keywords: Clinical characteristics, Population-based study, Congenital pseudarthrosis of the tibia

Posted Date: November 19th, 2021

DOI: https://doi.org/10.21203/rs.3.rs-1030379/v1

License: (c) (i) This work is licensed under a Creative Commons Attribution 4.0 International License. Read Full License 


\section{Abstract}

Background: Congenital pseudarthrosis of the tibia (CPT) is a refractory and rare disease. Because of its extremely low incidence, little is known about its clinical features. In this retrospective study, the aim of this study was to analyze the clinical characteristics of patients with CPT.

Methods: This is a retrospective study of children with CPT identified by radiological review. Investigations of CPT included general condition, the characteristics of CPT, treatment methods and surgical complications.

Results: We have collected 514 CPTs from 1999 to March 2020 in our hospital, 317 (61.67\%) boys, 197 (38.33\%) girls; 330 (62.86\%) in Crawford IV; 510 (97.14\%) in mid and distal 1/3 tibia; 481 (93.58\%) in less than 3 years of first appearance of symptom; 297 (57.78\%) in less than 3 years of the first visit of outpatient. The most common postoperative complication was ankle valgus (101, 39.60\%), followed by limb length discrepancy $\mathbb{} \mathbf{2} 1,35.69 \%)$, refracture $(38,14.90 \%)$, osteomyelitis $(15,5.88 \%)$ and removal of internal fixation $(10,3.93 \%)$.

Conclusions: CPT with higher incidence of Crawford IV frequently occurs in boys and middle or distal part of the tibia; most patients have the first appearance of symptom and the first visit of outpatient before 3 years; the major surgical complications were ankle valgus and limb length discrepancy.

\section{Background}

Congenital pseudarthrosis of the tibia (CPT) is a rare disease of the skeletal system in children, with a prevalence of 1 in 140,000 or $300000^{[1,2]}$. CPT related healthcare costs, work or study loss, and psychosocial problems result in a tremendous burden for children's family ${ }^{[3]}$. As the most populous country in the world, however, little information regarding CPT epidemiology is available in China.

Our clinical knowledge of CPT is still scarce and lacking unified understanding, because of its rare incidence. To this day, only three studies had more than 100 cases, two multi-center studies and one single-center study ${ }^{[4-6]}$. The incidence of CPT in the population was more recognized as 1 in 140,000, nonetheless, this data was reported in 1972 and only 13 patients were included ${ }^{\text {[2] }}$. The only large sample data is a multi-center study ${ }^{[7]}$ organized by The European Pediatric Orthopedic Society (EPOS) in 2000, which collected 340 cases from 20 hospitals in 13 countries. However, the above data are all from European countries, the different findings are based on small sample sizes. Additionally, to date, there has been no population-based epidemiological study investigating the etiology or pathogenesis of CPT. Therefore, a retrospective study based on a large sample should be conducted to better explore and enrich the relevant clinical information and knowledge of CPT.

Since the first CPT patient was admitted in our department from 1998, through hard work for nearly 20 years, more than 600 patients with CPT have been treated in our unit ${ }^{[8-18]}$. Therefore, based on a large number of cases, we established a Hunan CPT study database. The Hunan CPT study, which is a cross- 
sectional study of a general population sample of mainland Chinese, is designed to enhance current knowledge of CPT. As the previous studies have been constrained by the number of samples. In this study, the aims of the present paper are to introduce the clinical characteristics of patients with CPT.

\section{Methods}

\section{Study design and procedures}

We performed a retrospective CPT between 1998 and 2020, in the Human Children's Hospital. Patients who had CPT were identified by radiological review. The trial was conducted in accordance with the Declaration of Helsinki and approved by all local Ethics Committee (HCHLL-2019-37). All the patients provided written informed consent.

Investigations of CPT included patient' s general condition囚affected side, age of first appearance of symptom, age of the first visit of outpatient, age of first operation and whether combined with NF1 fibular cysts, definite injury and first visiting our hospital), the characteristics of CPT囚Crawford classification, the location of the pseudarthrosis, the location of the pseudarthrosis, lateral proximal tibia angle (LPTA), lateral distal tibia angle (LDTA) and whether there be pseudarthrosis of the fibula or cystic changes of the fibula囚, treatment methods and surgical complications.

\section{Inclusion and exclusion criteria}

We included participants aged under 16 years and provided complete data radiological review measurements. We excluded participants aged older 16 years old and others caused by osteomyelitis, trauma and malignant tumor.

\section{Measurements}

The location of CPT was a record as proximal $1 / 3$, mid $1 / 3$ and distal $1 / 3$. Briefly, we divided the tibial length into equal 3 parts and record the pseudarthrosis site in each of the proximal, middle or distal part

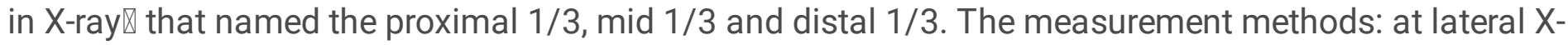
rays, the length of the pseudarthrosis to the proximal tibial epiphyseal growth plate (a) and the length of the pseudarthrosis to the distal tibial epiphyseal growth plate $(b)$, calculates $a /(a+b)=c(0<c<1) . c<1 / 3$, the pseudarthrosis was recorded as proximal $1 / 3$ of the tibia; $1 / 3 \leq \mathrm{C}<2 / 3$, the pseudarthrosis was recorded as mid $1 / 3$ of the tibia; $C \geq 2 / 3$, the pseudarthrosis was recorded at the distal $1 / 3$ of the tibia. The location of the pseudarthrosis of fibular was measured in the same way. They were recorded as proximal $1 / 3$, mid $1 / 3$ and distal $1 / 3$ of the fibula.

Crawford classification recorded at anteroposterior or lateral X-rays of the tibia/fibula which was taken at the first visit. We referred Springer $B$ et al method ${ }^{[19]}$ to define LDTA and LPTA. The CPT pathological classification we referred with the Crawford method ${ }^{[20]}$ and define them in 4 types.

\section{Statistical analysis}


The patients of CPT were numbered through the inpatient system and the imaging system, the general data of the corresponding children were entered into the EXCEL2019 form. All data was analyzed using STATA (Version 13.0, StataCorp LP, TX, USA). Two-sample t-tests were used to analyse continuous data, the chi-square test was used for categorical data.

\section{Results}

\section{Patient's general condition}

Between 1998 and 2020, 514 children with a recorded diagnosis of CPT. 317 (61.67\%) boys, 197 (38.33\%) girls; $253(49.22 \%)$ in left, $250(48.63 \%)$ in right and $11(2.15 \%)$ in bilateral of affected side; 368 $(71.60 \%)$ in birth-<1 year, $113(21.98 \%)$ in $\geq 1$ - $₫ 3$ years and $33(6.42 \%)$ in $\geq 3$ years of first appearance of symptom; 66 (12.83\%) in birth-<1 year, 231 (44.94\%) in $\geq 1$ - $₫ 3$ years and $217 \otimes 42.23 \% \bigotimes$ in $\geq 3$ years of the first visit of outpatient; $51(11.70 \%)$ in birth-<1 year, 170 (38.99\%) in $\geq 1$ - \3years and $215(49.31 \%)$ in

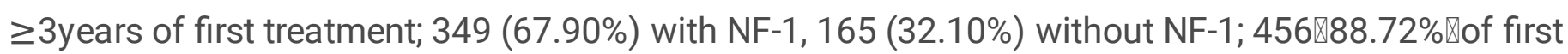
treatment in our hospital, 58 (11.28\%) of first treatment not in our hospital; 388 (75.49\%) without definite injury, 126 (25.51\%) with definite injury which included 81 (64.29\%) walking fall, 9 (7.12\%) bruise with weight, 8 (6.35\%) sprain, 4 (3.17\%) aggravating activities and 24 (19.05\%) falling accidents. (Table 1)

\section{The radiologic features of CPT}

Crawford type IV had the largest number of 276 cases, accounting for $53.70 \%$ of all types, and the other types were Crawford type I 33 (6.29\%), Crawford type II 106 (20.19\%) and Crawford type III 56 (10.67\%) in turn according to the proportion. For the pseudarthrosis and fibular condition, 276 (53.70\%) in CPT with pseudarthrosis of the fibula and $238(46.30 \%)$ in CPT without pseudarthrosis of the fibula; $44(8.56 \%)$ in CPT with cystic changes of the fibula and $470(91.44 \%)$ in CPT without cystic changes of the fibula. For the location of CPT, main locations of the lesion were in the middle and distal tibia in the study, 14 (2.67\%) in proximal 1/3 tibia, $191(36.38 \%)$ in mid 1/3 tibia and $319(60.76 \%)$ in distal $1 / 3$ tibia. Genu valgum and ankle valgus had 101 (38.11\%) which were the main manifestations of CPT. To explore the statistical difference, only pseudarthrosis of the fibula was statistically between boys and girls $(p=0.015)$ (Table 2).

\section{Treatment methods and surgical complications}

In our database, 78 (15.18\%) cases received conservative treatment and 436 (84.82\%) cases received surgical operation. The incidences of surgical complications are the following: 101 (39.60\%) cases occurred ankle valgus ,91 (35.69\%) cases occurred limb length discrepancy, 38 (14.90\%) cases occurred refracture, $15(5.88 \%)$ cases occurred osteomyelitis, and 10 (3.93\%) cases occurred displacement of internal fixation (Table 3).

\section{The map of regional distribution}


Regional distribution of patients was divided by province, autonomous region and direct jurisdiction cities. 514 cases came from 29 provinces or autonomous regions or direct jurisdiction cities, including 65 (12.67\%) in Hunan province, 44 (8.58\%) in Henan province, 34 (6.42\%) in Shandong province, 28 in Jiangsu province, 27 (5.26\%) in Guangxi Zhuang Autonomous Region, 27 (5.26\%) in Hubei province, 26 $(5.07 \%)$ in each Guangdong province, and Jiangxi province, $25(4.87 \%)$ in Hebei province, $25(4.87 \%)$ in Zhejiang province, 21 (4.09\%) in Anhui province, 17 (3.31\%) in each Gansu province, Liaoning province and Yunnan province, $14(2.73 \%)$ in each Fujian province and Shanxi province, $13(2.53 \%)$ in Jilin province, $12(2.34 \%)$ in each Guizhou province and Sichuan province, $9(1.75 \%)$ in Shanxi province, 8 (1.56\%) in Xinjiang Uygur Autonomous Region, 6 (1.17\%)in each Heilongjiang province and Nei Monggol Autonomous Region, 5 (0.97\%) in each Beijing and Chongqing, 4 (0.78\%) in Tianjing, $3(0.58 \%)$ in Ningxia Hui Autonomous Reigion, 2 (0.39\%) in each Hainan province and Shanghai (Figure 1).

\section{Discussion}

In this study, we first present a huge cases of CPT described retrospective study, and defined them clinical features from the parts of general condition, radiological and clinical characteristic. Thus, we bring a much more deep knowledge of CPT from Chinese aspect.

In this study, we have collected 514 cases which came from 29 provinces or autonomous regions and direct jurisdiction cities. Hunan province had the highest number of cases with 65 (12.67\%), in the top 10 provinces with the largest number of cases, only Guangxi Zhuang Autonomous Region 27 (5.26\%) and Jiangxi province $26(5.07 \%)$ was not among the top 10 provinces or autonomous regions and direct jurisdiction cities with the largest population in China. Provinces or autonomous regions and direct jurisdiction cities with larger population had more cases, but Hunan provinces weren't the top one with the largest population in China, which may be related to the geographical location of our hospital.

CPT is a rare pathology occurring in between $1 / 140,000$ and $1 / 250,000$ births $^{[21-23]}$ and is one of the most complex orthopedic situations in pediatrics. Based on the morbidity reported above, in recent 10 years, the number of newborns in China which from official data reports was 157.56 million, from this aspect, this may reflect the number of CPT patients was closed to 630-1125 cases. Of the 514 cases collected in our hospital, 424 cases were collected from 2011 to 2020, and 90 cases were collected from 1999 to 2010 . It means that our one center has treated nearly $40 \%$ of the national CPT since 2011.

Currently, the timing of surgery for CPT is a controversial issue ${ }^{[24]}$. EPOS recommend avoiding surgery for CPT in patients younger than 3 years old, operation should be postponed to the age of 5 years, otherwise, patients may have a worse prognosis ${ }^{[7]}$. Harding ${ }^{[25]}$ had similarly recommended deferred surgery to the age of 4 years. However, Shah $\mathrm{H}^{[26]}$ reported that the achievement of bone union in young children can minimize the abnormal growth and lower limb shortening. Joseph ${ }^{[27]}$ reported that the bone union of CPT occurred in 12 out of $13(92 \%)$ children treated before the age of 3 years. Liu ${ }^{[14]}$ reported 42 patients 
with CPT which were recruited and analyzed, overall, the frequency of bone union was higher in children with CPT operated before reaching 3 years of age, Liu suggested that there is no need to defer surgery for CPT until the child is older than 3 years of age. Considering this controversial issue, in our study, age of first appearance of symptom, first visit of outpatient and first operation were divided into three groups which were birth-<1year, $\geq 1-<3$ years and $\geq 3$ years. In this study, the age of first appearance of symptom before 3 years had 481 (93.58\%) cases and after 3 years had $33(6.42 \%)$ cases; the age of the first visit of outpatient before 3 years had 297 (57.78\%) cases and after 3 years had $217(42.22 \%)$ cases ;

$221(50.69 \%)$ cases had operation before 3 years old and 215 (49.31\%) cases had operation after 3 years old; this phenomenon which operation before 3 years was as common as operation after 3 years may be related to the age of the first visit of outpatient.

Pseudarthrosis of the fibula (CPF) is frequently associated with CPT, but it becomes uncommon when it's isolated. Isolated CPF is usually considered a less severe condition than CPT. However, its site most frequently near the ankle leads to severe valgus and instability of this weight bearing joint ${ }^{[24,28]}$. In Liu's study ${ }^{[10]}$, patients with fibular pseudarthrosis had a high incidence of refracture and ankle valgus, he suggested that attention should be paid to the presence of fibular pseudarthrosis when managing CPT. There were 276 (53.70\%) CPF treated in 514 cases of this study, meanwhile 44 (8.56\%) cases with cystic changes of his fibula. There were statistical differences in the prevalence of $\mathrm{CPF}$, but no statistical differences in cystic changes of his fibula.

We found that Crawford IV $(330,62.86 \%)$ CPT had the greatest cases, which may be associated with hyperactivity. We treated Crawford IV CPT and developed into Crawford IV CPT with operation. It has been well documented that external fixation in children and adolescents have a significant physical and physiological impact, with studies reporting pain and consequent sleeping problems in approximately half of the patients ${ }^{[29]}$. The operation complications related primarily to the use of an external or internal device, residual limb-length discrepancy and valgus deformity are commonly reported with an overall complication rate of $30-100 \%{ }^{[30]}$. In our study, the complication also concluded ankle valgus, limb length discrepancy, refrature, osteomyelitis and removal of internal fixation. ankle valgus $(101,39.60 \%)$ and limb length discrepancy $(91,35.69 \%)$. The present study is a retrospective review limited by the heterogeneity of the available data and follow-up. Firstly, this study was a cross-sectional analysis and didn't provide prognostic or therapeutic recommendations for cohort studies. Secondly, this study was a single-centre analysis. Although our cases came from all over the country, there was still bias. We should combine The China Pediatric Orthopedic Association with expanding multi-center research in future studies, with further detailed documentation, it may be possible to clarify many more issues ${ }^{[31]}$.

\section{Conclusion}

Until now, we have collected 514 cases of CPT, which was the largest single-centre study. CPT with higher incidence of Crawford IV frequently occurs in boy and middle or distal tibia; the major surgical complications were ankle valgus and limb length discrepancy. In subsequent studies, we will further 
report pathologic mechanism, surgical methods, complications, and prognosis of CPT through prospective studies.

\section{Declarations}

\section{Author Contributions:}

Conceptualization, Y.Z, G.Y. and H.M.; methodology, Y.Z, Y.L and Q.T; validation, K.L., G.Z. and Y.L.; formal analysis, Q.T and Y.Z.; investigation, Y.Z and Q.T.; resources, G.Y. and H.M.; data curation, Y.Z.; writingoriginal draft preparation, Y.Z.; writing-review and editing, Y.Z, G.Y. and H.M.; supervision, H.M. and G.Z.; project administration,G.Y. and H.M.; funding acquisition,G.Y. and H.M. All authors have read and agreed to the published version of the manuscript.

\section{Funding}

This work was funded by the National Natural Science Foundation of China (82101818 to GY), Clinical Research Center for Limb Deformity of Children in Hunan Province (2019SK4006 to HM).

\section{Ethics approval and consent to participate}

The study was approved by the Institutional Review Board of Ethics Committee of Hunan Children's Hospital (protocol code HCHLL-2019-37). Written informed consent has been obtained from the patients to publish this paper.

Data Availability Statement: Not applicable.

Acknowledgments: Not applicable.

Consent for publication: Not applicable.

Conflicts of Interest: The authors declare no conflict of interest.

\section{References}

1. Ohnishi I, Sato W, Matsuyama J, Yajima H, Haga N, Kamegaya M, Minami A, Sato M, Yoshino S, Oki T, Nakamura K. Treatment of congenital pseudarthrosis of the tibia: a multicenter study in Japan. Journal of pediatric orthopedics 2005, 25(2): 219-224.

2. Andersen KS. Congenital angulation of the lower leg and congenital pseudarthrosis of the tibia in Denmark. Acta orthopaedica Scandinavica 1972, 43(6): 539-549.

3. McCarthy RE. Amputation for congenital pseudarthrosis of the tibia. Indications and techniques. Clinical orthopaedics and related research 1982(166): 58-61.

4. Hefti F, Bollini G, Dungl P, Fixsen J, Grill F, Ippolito E, Romanus B, Tudisco C, Wientroub S. Congenital pseudarthrosis of the tibia: history, etiology, classification, and epidemiologic data. Journal of 
pediatric orthopedics Part B 2000, 9(1): 11-15.

5. Shah H, Joseph B, Nair BVS, Kotian DB, Choi IH, Richards BS, Johnston C, Madhuri V, Dobbs MB, Dahl M. What Factors Influence Union and Refracture of Congenital Pseudarthrosis of the Tibia? A Multicenter Long-term Study. Journal of pediatric orthopedics 2018, 38(6): e332-e337.

6. Sofield HA. Congenital pseudarthrosis of the tibia. Clinical orthopaedics and related research 1971, 76: 33-42.

7. Grill F, Bollini G, Dungl P, Fixsen J, Hefti F, Ippolito E, Romanus B, Tudisco C, Wientroub S. Treatment approaches for congenital pseudarthrosis of tibia: results of the EPOS multicenter study. European Paediatric Orthopaedic Society (EPOS). Journal of pediatric orthopedics Part B 2000, 9(2): 75-89.

8. Liu Y, Yang G, Liu K, Wu J, Zhu G, Tang J, Zheng Y, Mei H. Combined surgery with 3-in-1 osteosynthesis in congenital pseudarthrosis of the tibia with intact fibula. 2020, 15(1): 62.

9. Yan A, Mei HB, Liu K, Wu JY, Tang J, Zhu GH, Ye WH. Wrapping grafting for congenital pseudarthrosis of the tibia: A preliminary report. Medicine 2017, 96(48): e8835.

10. Liu YX, Mei HB, Zhu GH, He RG, Liu K, Tang J, Wu JY, Ye WH, Hu X, Tan Q, Yan A, Huang SX, Tan XQ, Lei T. Relationship between postoperative complications and fibular integrity in congenital pseudarthrosis of the tibia in children. World journal of pediatrics : WJP 2017, 13(3): 261-266.

11. Liu YX, Mei HB, Liu K, Wu JY, Tang J, He RG, Zhu GH, Ye WH, Hu X, Yan A, Yi YZ, Zhang N. Correlative study between $X$-ray type after healing of congenital pseudarthrosis of the tibia in children and postoperative refracture. Zhonghua wai ke za zhi [Chinese journal of surgery] 2016, 54(6): 456-460.

12. Zhu GH, Mei HB, He RG, Liu YX, Liu K, Tang J, Wu JY. Combination of intramedullary rod, wrapping bone grafting and llizarov's fixator for the treatment of Crawford type IV congenital pseudarthrosis of the tibia: mid-term follow up of 56 cases. BMC musculoskeletal disorders 2016, 17(1): 443.

13. Zhu GH, Mei HB, He RG, Liu K, Tang J, Wu JY. Effect of distraction osteogenesis in patient with tibial shortening after initial union of Congenital Pseudarthrosis of the Tibia (CPT): a preliminary study. BMC musculoskeletal disorders 2015, 16: 216.

14. Liu Y, Mei H, Zhu G, Liu K, Wu J, Tang J, He R. Congenital pseudarthrosis of the tibia in children: should we defer surgery until 3 years old? Journal of pediatric orthopedics Part B 2018, 27(1): 17-25.

15. Deng H, Mei H, Wang E, Li Q, Zhang L, Canavese F. The association between fibular status and frontal plane tibial alignment post-union in congenital pseudarthrosis of the tibia. Journal of children's orthopaedics 2021, 15(3): 261-269.

16. Liu Y, Yang G, Zhu G, Tan Q, Wu J, Liu K, Tang J, Mei H. Application of the "telescopic rod" in a combined surgical technique for the treatment of congenital pseudarthrosis of the tibia in children. Journal of orthopaedic surgery and research 2021, 16(1): 532.

17. Zhu G, Zheng Y, Liu Y, Yan A, Hu Z, Yang Y, Xiang S, Li L, Chen W, Peng Y, Zhong N, Mei H. Identification and characterization of NF1 and non-NF1 congenital pseudarthrosis of the tibia based on germline NF1 variants: genetic and clinical analysis of 75 patients. Orphanet J Rare Dis 2019, 14(1): 221. 
18. Yang G, Yu H, Liu Y, Ye W, Zhu G, Yan A, Tan Q, Mei H. Serum-derived exosomes from neurofibromatosis type 1 congenital tibial pseudarthrosis impaired bone by promoting osteoclastogenesis and inhibiting osteogenesis. Experimental biology and medicine (Maywood, NJ) 2021, 246(2): 130-141.

19. Springer B, Bechler U, W. W, K. R, C. B, F. B. The influence of femoral and tibial bony anatomy on valgus OA of the knee. Knee surgery, sports traumatology, arthroscopy : official journal of the ESSKA 2020, 28(9): 2998-3006.

20. Crawford AH, Jr., Bagamery N. Osseous manifestations of neurofibromatosis in childhood. Journal of pediatric orthopedics 1986, 6(1): 72-88.

21. Dohin B, Kohler R. Masquelet's procedure and bone morphogenetic protein in congenital pseudarthrosis of the tibia in children: a case series and meta-analysis. Journal of children's orthopaedics 2012, 6(4): 297-306.

22. Paterson D. Congenital pseudarthrosis of the tibia. An overview. Clinical orthopaedics and related research 1989(247): 44-54.

23. Andersen KS. Congenital pseudarthrosis of the tibia and neurofibromatosis. Acta orthopaedica Scandinavica 1976, 47(1): 108-111.

24. Khan T, Joseph B. Controversies in the management of congenital pseudarthrosis of the tibia and fibula. The bone \& joint journal 2013, 95-b(8): 1027-1034.

25. Hardinge K. Congenital anterior bowing of the tibia. The significance of the different types in relation to pseudarthrosis. Annals of the Royal College of Surgeons of England 1972, 51(1): 17-30.

26. Shah H, Rousset M, Canavese F. Congenital pseudarthrosis of the tibia: Management and complications. Indian journal of orthopaedics 2012, 46(6): 616-626.

27. Joseph B, Somaraju VV, Shetty SK. Management of congenital pseudarthrosis of the tibia in children under 3 years of age: effect of early surgery on union of the pseudarthrosis and growth of the limb. Journal of pediatric orthopedics 2003, 23(6): 740-746.

28. Cherrad T, Zejjari H, Bousbaä H, Louaste J, Rachid K, Amhajji L. Isolated congenital pseudarthrosis of the fibula: A report of two cases and review of the literature. Journal of clinical orthopaedics and trauma 2019, 10(4): 797-799.

29. Choi IH, Cho TJ, Moon HJ. Ilizarov treatment of congenital pseudarthrosis of the tibia: a multitargeted approach using the Ilizarov technique. Clinics in orthopedic surgery 2011, 3(1): 1-8.

30. Gorbulin AE, Savenkov DI, Latyshev NN, Galushka FP. Some characteristics of the differential diagnosis of coniotuberculosis. Problemy tuberkuleza 1976(7): 57-60.

31. Wu J, Lu AD, Zhang LP, Zuo YX, Jia YP. Study of clinical outcome and prognosis in pediatric core binding factor-acute myeloid leukemia. Zhonghua xue ye xue za zhi = Zhonghua xueyexue zazhi 2019, 40(1): 52-57.

\section{Tables}


Table 1 Patient' s general condition

Page 10/15 


\begin{tabular}{|c|c|c|c|c|}
\hline & Male $₫ n=317 \rrbracket$ & Female $\bigotimes n=197 \rrbracket$ & Statistical value & $P$ value \\
\hline \multicolumn{5}{|l|}{ Affected Side } \\
\hline Left & 146 & 107 & 3.5675 & 0.168 \\
\hline Right & 163 & 87 & & \\
\hline Bilateral & 8 & 3 & & \\
\hline \multicolumn{5}{|c|}{ Age of first appearance of symptom } \\
\hline birth- $\llbracket 1$ year & 235 & 133 & 3.0079 & 0.22 \\
\hline$\geq 1$-囚3years & 65 & 48 & & \\
\hline$\geq 3$ years & 17 & 16 & & \\
\hline \multicolumn{5}{|c|}{ Age of the first visit of outpatient } \\
\hline birth- $₫ 1$ year & 38 & 28 & 1.537 & 0.464 \\
\hline$\geq 1$ - $₫$ 3years & 149 & 82 & & \\
\hline$\geq 3$ years & 130 & 87 & & \\
\hline \multicolumn{5}{|c|}{ Age of first operation } \\
\hline birth- $₫ 1$ year & 31 & 20 & 1.21 & 0.54 \\
\hline$\geq 1$-₫3years & 113 & 57 & & \\
\hline$\geq 3$ years & 132 & 83 & & \\
\hline \multicolumn{5}{|l|}{ NF-1 (Yes/No) } \\
\hline yes & 212 & 137 & 0.396 & 0.529 \\
\hline no & 105 & 60 & & \\
\hline \multicolumn{5}{|c|}{ First visit of outpatient in our hospital (Yes/No) } \\
\hline yes & 281 & 175 & 0.00612 & 0.9376 \\
\hline no & 36 & 22 & & \\
\hline \multicolumn{5}{|c|}{ With/without definite injury } \\
\hline yes & 72 & 54 & 1.4493 & 0.229 \\
\hline no & 245 & 143 & & \\
\hline walking fall & 51 & 30 & & \\
\hline bruise with weight & 7 & 2 & & \\
\hline sprain & 7 & 1 & & \\
\hline
\end{tabular}


$\begin{array}{lll}\text { aggravating activities } & 3 & 1\end{array}$

falling accidents $\quad 4 \quad 20$

Table 2 The characteristics of CPT

\begin{tabular}{|c|c|c|c|c|}
\hline & Male $\rrbracket n=317 \rrbracket$ & Female $₫ n=197 \rrbracket$ & Statistical value & $P$ value \\
\hline \multicolumn{5}{|c|}{ Crawford classification $(\mathrm{n} 1+\mathrm{n} 2$ means $\mathrm{n} 1=$ lateral and $\mathrm{n} 2=$ bilateral) } \\
\hline I & 20 & $12+1$ & 1.78 & 0.618 \\
\hline II & $54+6$ & $45+1$ & & \\
\hline III & $33+3$ & $18+2$ & & \\
\hline IV & $202+7$ & $119+2$ & & \\
\hline \multicolumn{5}{|c|}{ pesudarthrosis of the fibula (Yes/No) } \\
\hline Yes & 183 & 93 & 5.9228 & 0.015 \\
\hline No & 134 & 104 & & \\
\hline \multicolumn{5}{|c|}{ Cystic changes of the fibula (Yes/No) } \\
\hline Yes & 29 & 15 & 0.3653 & 0.546 \\
\hline No & 288 & 182 & & \\
\hline \multicolumn{5}{|c|}{ The location of the pesudarthrosis $(\mathrm{n} 1+\mathrm{n} 2$ means $\mathrm{n} 1=$ =lateral and $\mathrm{n} 2=$ bilateral) } \\
\hline Proximal $1 / 3$ & 6 & $7+1$ & 3.9795 & 0.137 \\
\hline Mid 1/3 & $110+2$ & $76+3$ & & \\
\hline Distal 1/3 & $192+14$ & $111+2$ & & \\
\hline \multicolumn{5}{|c|}{ LPTA and LDTA } \\
\hline LPTA & $86.91 \pm 5.002$ & $86.98 \pm 5.456$ & 0.1437 & 0.8858 \\
\hline LDTA & $87.573 \pm 10.928$ & $87.079 \pm 10.432$ & -0.5088 & 0.6111 \\
\hline
\end{tabular}

Table 3 Treatment methods and surgical complications 


\begin{tabular}{|lllll|}
\hline & Male & Female & Statistical value & P value \\
\hline Treatment methods & & & & \\
\hline Non-operation & 41 & 37 & & 0.072 \\
\hline operation & 276 & 160 & 3.227 & \\
\hline Surgical complication & & & & 0.475 \\
\hline Ankle valgus & 63 & 38 & 3.5205 & \\
\hline Limb length discrepancy & 56 & 35 & & \\
\hline Refracture & 18 & 20 & & \\
\hline Osteomyelitis & 8 & 7 & & \\
\hline Removal of Internal fixation & 7 & 3 & & \\
\hline
\end{tabular}

Figures 


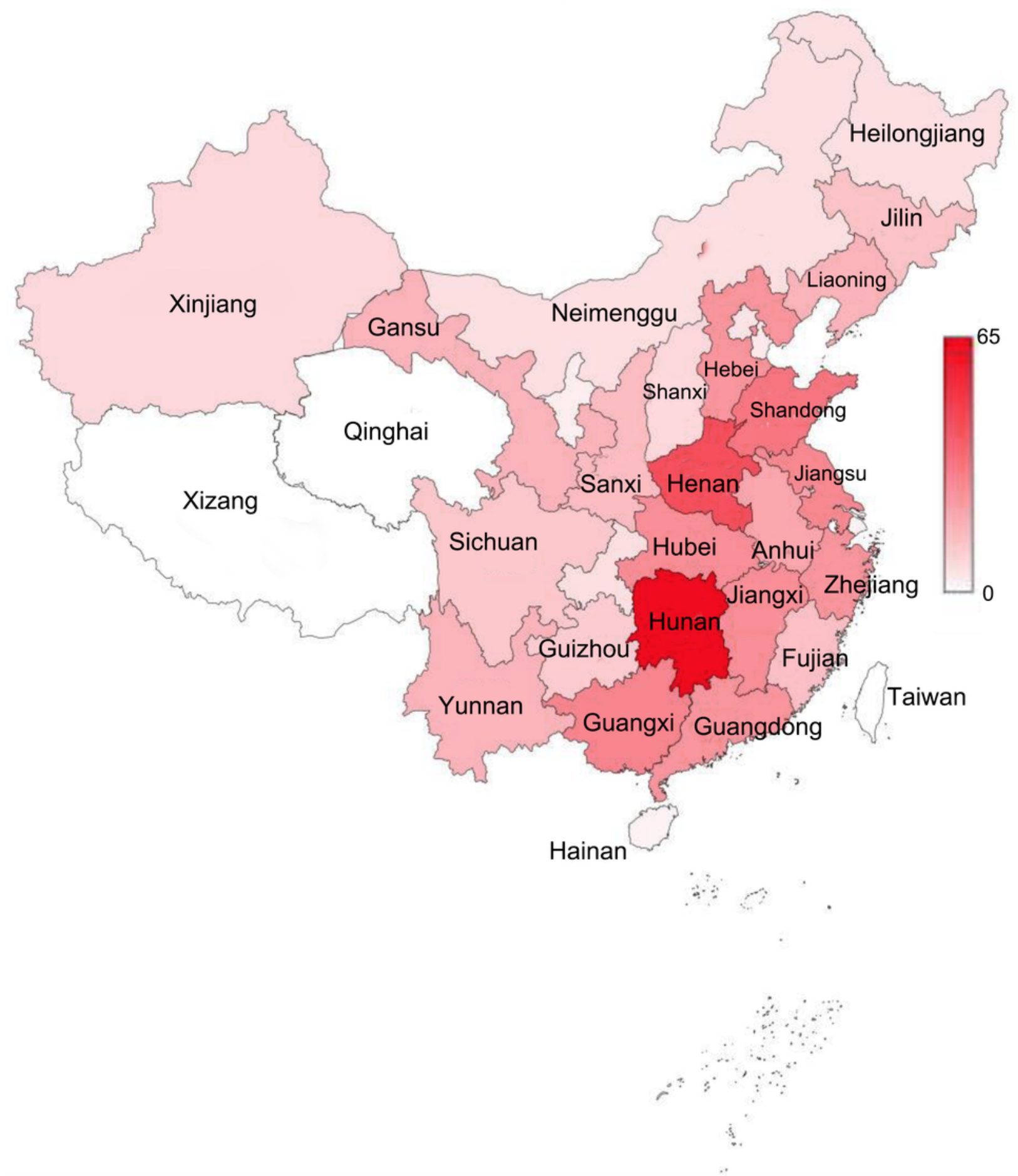

\section{Figure 1}

Regional distribution of patients was divided by province, autonomous region and direct jurisdiction cities. 514 cases came from 29 provinces or autonomous regions or direct jurisdiction cities, including 65 (12.67\%) in Hunan province, 44 (8.58\%) in Henan province, 34 (6.42\%) in Shandong province, 28 in Jiangsu province, 27 (5.26\%) in Guangxi Zhuang Autonomous Region, 27 (5.26\%) in Hubei province, 26 (5.07\%) in each Guangdong province, and Jiangxi province, 25 (4.87\%) in Hebei province, 25 (4.87\%) in 
Zhejiang province, 21 (4.09\%) in Anhui province, 17 (3.31\%) in each Gansu province, Liaoning province and Yunnan province, $14(2.73 \%)$ in each Fujian province and Shanxi province, $13(2.53 \%)$ in Jilin province, $12(2.34 \%)$ in each Guizhou province and Sichuan province, $9(1.75 \%)$ in Shanxi province, 8 (1.56\%) in Xinjiang Uygur Autonomous Region, 6 (1.17\%)in each Heilongjiang province and Nei Monggol Autonomous Region, $5(0.97 \%)$ in each Beijing and Chongqing, 4 (0.78\%) in Tianjing, 3 (0.58\%) in Ningxia Hui Autonomous Reigion, 2 (0.39\%) in each Hainan province and Shanghai. 